\title{
Shielding Analysis of Metal Hydride-based Materials for Both Neutron and Gamma Rays Using Monte Carlo Simulation
}

\author{
Jeongkwon Kwak ${ }^{1}$, Boravy Muth ${ }^{2}$, Hyeon-Woo Yang ${ }^{1}$, Chang Je Park ${ }^{2}$, \\ Woo Seung Kang ${ }^{3}$, and Sun-Jae Kim ${ }^{1, *}$ \\ ${ }^{I}$ Department of Nanotechnology and Advanced Materials Engineering, Sejong University, Seoul 05006, Republic of Korea \\ ${ }^{2}$ Department of Nuclear Engineering, Sejong University, Seoul 05006, Republic of Korea \\ ${ }^{3}$ Department of Metallurgical and Materials Engineering, Inha Technical College, Incheon 22212, Republic of Korea
}

\begin{abstract}
Radiation causes damage to the human body, the environment, and electronic equipment. Shielding against neutron and gamma rays is particularly difficult because of their strong ability to penetrate materials. Conventional gamma ray shields are typically made of materials containing $\mathrm{Pb}$. However, they pose problems in that $\mathrm{Pb}$ is a heavy metal, and human poisoning and/or pollution can result from the manufacturing, use, and disposal of these materials. In addition, neutron rays are shielded by materials rich in $\mathrm{H}_{2}$ or concrete. In the case of the latter, the manufacturing cost is high. Thus, it is necessary to develop a new multilayer structure that can shield against both neutron and gamma rays. We set up a simulation model of a multilayered structure consisting of metal hydrides and heavy metals, and then evaluated the simulations using Monte Carlo N-Particle Transport Code. Monte Carlo simulation is an accurate method for simulating the interaction between radiation and materials, and can be applied to the transport of radiation particles to predict values such as flux, energy spectrum, and energy deposition. The results of the study indicated the multilayer structure of $\mathrm{ZrH}_{2}, \mathrm{U}$, and $\mathrm{W}$ could shield both neutron and gamma rays, thus showing potential as a new shielding material to replace $\mathrm{Pb}$ and concrete.
\end{abstract}

(Received July 6 2021; Accepted September 15, 2021)

Keywords: monte carlo, neutron, gamma ray, shielding, multilayer, MCNP

\section{Introduction}

Nuclear accidents such as the 1986 accident in Chernobyl and the more recent one in Fukushima resulted in the massive release of radioactive materials into the environment. Not only did they pollute the soil and ocean, but they also caused fatal damage to humans as well as electronic equipment [1, 2]. In general, radiation comprises alpha, beta, and gamma rays. Alpha and beta rays have large retention energies but can be easily shielded against. Gamma rays and neutrons, in contrast, have high permeabilities and are difficult to be shielded against. Thus, they pose a relatively higher risk [3]. As a result, radiation shielding materials are required that can suitably shield and protect the human body and electronic

- 곽정권 · Boravy Muth · 양현우: 연구원, 박창제 · 강우승 · 김선재: 교수 *Corresponding Author: Sun-Jae Kim

[Tel: +82-2-3408-3780, E-mail: sjkim1@sejong.ac.kr]

Copyright (c) The Korean Institute of Metals and Materials equipment from radiation. In particular, shielding materials are essential in various fields of applications such as textiles, nuclear energy, aerospace, national defense, and medicine $[4,5]$.

Conventional gamma ray shields are mainly made of materials containing $\mathrm{Pb}$. High-density materials are effective at attenuating gamma rays, and they are generally produced using inexpensive $\mathrm{Pb}$, such as an intact $\mathrm{Pb}$ plate or a film composed of $\mathrm{Pb}$ powder or $\mathrm{PbS}$ blended with an excess of polymer resin. However, shielding films containing $\mathrm{Pb}$ are heavy, and can cause human poisoning and/or pollution due to the presence of $\mathrm{Pb}$ during the manufacturing, use, and/or disposal processes [6,7]. For neutron beams, materials such as water, paraffin, and graphite have a high $\mathrm{H}_{2}$ content and a low atomic number, which slows down the fast neutron flux. Concrete mixed with materials such as $\mathrm{B}$ and $\mathrm{Cd}$ can be used to absorb decelerated neutron beams [8]. However, neutron beams and gamma rays have different attenuation characteristics 
with respect to shielding materials, and it is difficult to effectively shield against both kinds of rays using a single material. Thus, a multilayer structure is generally required. As the multilayer shielding material must be considerably thick, the manufacturing cost is high. In addition, the frequently contain harmful substances, such as $\mathrm{Pb}$.

There have been many attempts to develop new shielding materials that can overcome the disadvantages of conventional neutron and gamma ray shielding materials. In the field of nuclear energy, radiation shielding experiments are simulated with a computer due to the prevailing limitations with suitable locations/facilities and equipment. Such simulations are typically carried out using the Monte Carlo N-Particle Transport Code (MCNP) [9,10]. The MCNP is known to be an accurate technique for simulating interactions between radiation and materials. It can be applied to study radiation particle transport and to predict values such as flux, energy spectra, and energy deposition. The MCNPX code is a representative program of the Monte Carlo method, and various studies on radiation shielding and protection have been carried out in Korea using this code [11-15]. Recently, MCNP6, which combines the functions of MCNP5 and MCNPX, was introduced. This code is known to be a more accurate and simpler model compared to both

(a)

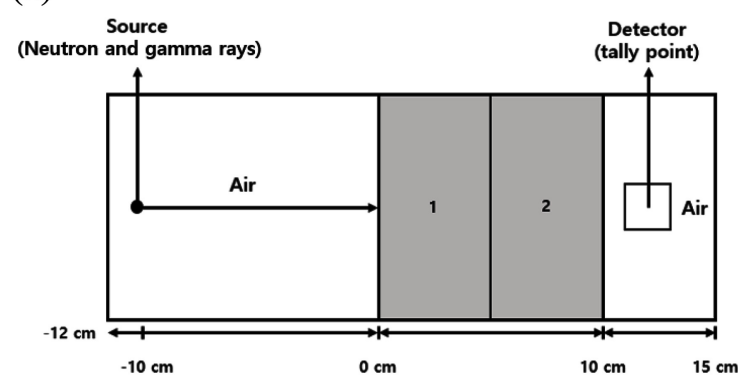

(b)

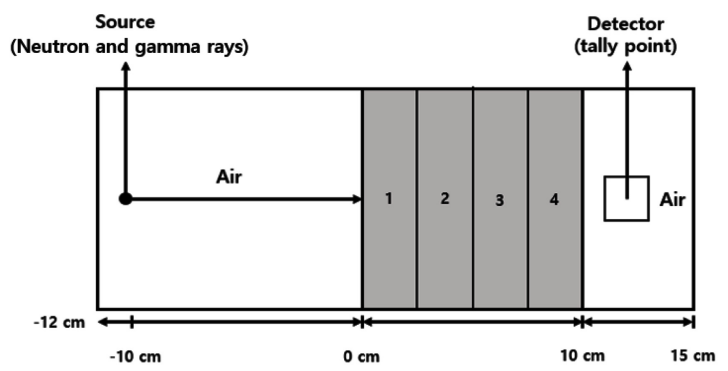

2.1 Description of the simulation code and analysis model

The MCNP6 code was used for the simulation. The ENDF/ B-VII.1 cross section library and Mcplib84 were used for the neutron ray calculations and gamma ray calculations, respectively. The source definition uses an F4 card, which detects the surface flux, and an F5 card, which detects the dotted flux. The analysis model targets a shielding material consisting of a regular hexahedron with sides of $10 \mathrm{~cm}$ each. Neutron and photon particles propagate in a straight line

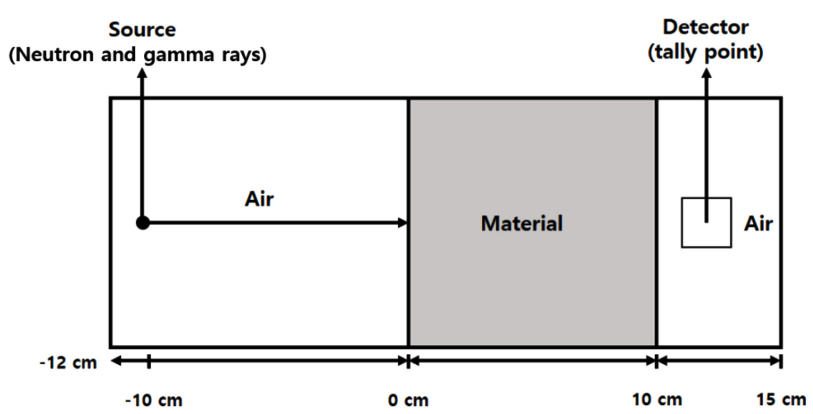

Fig. 1. Design of the shielding analysis model based on MCNP6.

(c)

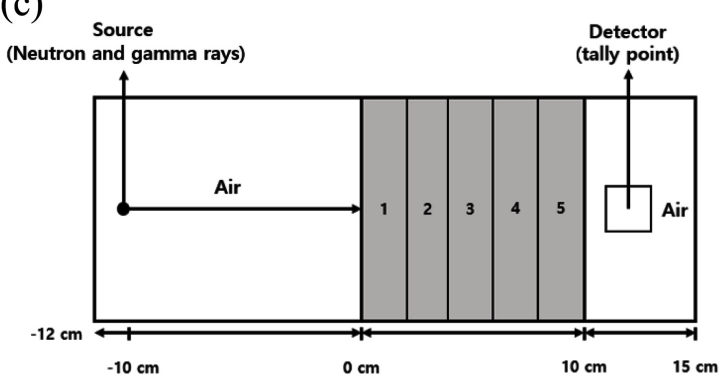


along the $\mathrm{x}$-axis and enter the shielding material at $10 \mathrm{~cm}$ (Fig. 1). The source and detector, except the shielding material, were simulated by artificially setting the air atmosphere to match the actual conditions. In this case, the size of the source energy ranged from 0.5 to $1 \mathrm{MeV}$, and the number of energy particles in the source was assumed to range from $10^{7}$ to $10^{8}$ photons or neutrons.

\subsection{Description of the multilayer simulation model}

We also set up a multilayer simulation model because of the secondary gamma rays generated when the shielding material is irradiated. Figure $2(a-c)$ is a schematic of a multilayer shielding analysis model. Parts (a), (b), and (c) show a simulation model consisting of two, four, and five layers, respectively. In the two-layer model, the first layer consists of a $5 \mathrm{~cm}$ thick metal hydride, and the second layer consists of a $5 \mathrm{~cm}$ thick heavy metal. In the four-layer model, the first and third layers consist of a $2.5 \mathrm{~cm}$ thick metal hydride, and the second and fourth layers consist of $2.5 \mathrm{~cm}$ thick heavy metals. In the five-layer model, the first, third, and fifth layers consist of a $2 \mathrm{~cm}$ thick metal hydride, and the second and fourth layers are composed of a $2 \mathrm{~cm}$ thick heavy metal.

Table 1. Neutron ray flux comparisons for the multilayer models (neutron $/ \mathrm{cm}^{2} \cdot \mathrm{s}$ ) (relative error $=0.03$ to 0.58$)$.

\begin{tabular}{cccc}
\hline $\mathrm{MATERIAL}$ & 2LAYERS & 4LAYERS & 5LAYERS \\
\hline $\mathrm{MgH}_{2} / \mathrm{W}$ & $3.8761 \mathrm{E}-05$ & $3.9253 \mathrm{E}-05$ & $4.3728 \mathrm{E}-05$ \\
$\mathrm{MgH}_{2} / \mathrm{U}$ & $4.8566 \mathrm{E}-05$ & $4.7750 \mathrm{E}-05$ & $5.2386 \mathrm{E}-05$ \\
$\mathrm{MgH}_{2} / \mathrm{Hf}$ & $4.0553 \mathrm{E}-05$ & $4.8986 \mathrm{E}-05$ & $4.1254 \mathrm{E}-05$ \\
$\mathrm{MgH}_{2} / \mathrm{Tl}$ & $5.5927 \mathrm{E}-05$ & $6.1104 \mathrm{E}-05$ & $6.3786 \mathrm{E}-05$ \\
$\mathrm{TiH}_{2} / \mathrm{W}$ & $2.4758 \mathrm{E}-05$ & $2.6654 \mathrm{E}-05$ & $2.8360 \mathrm{E}-05$ \\
$\mathrm{TiH}_{2} / \mathrm{U}$ & $3.1205 \mathrm{E}-05$ & $3.5278 \mathrm{E}-05$ & $3.6388 \mathrm{E}-05$ \\
$\mathrm{TiH}_{2} / \mathrm{Hf}$ & $2.3862 \mathrm{E}-05$ & $3.1850 \mathrm{E}-05$ & $2.6470 \mathrm{E}-05$ \\
$\mathrm{TiH}_{2} / \mathrm{Tl}$ & $3.7234 \mathrm{E}-05$ & $4.2561 \mathrm{E}-05$ & $3.8903 \mathrm{E}-05$ \\
$\mathrm{ZrH}_{2} / \mathrm{W}$ & $2.9151 \mathrm{E}-05$ & $3.0417 \mathrm{E}-05$ & $3.4784 \mathrm{E}-05$ \\
$\mathrm{ZrH}_{2} / \mathrm{U}$ & $3.8873 \mathrm{E}-05$ & $4.1030 \mathrm{E}-05$ & $4.3368 \mathrm{E}-05$ \\
$\mathrm{ZrH}_{2} / \mathrm{Hf}$ & $2.9799 \mathrm{E}-05$ & $3.7416 \mathrm{E}-05$ & $3.0196 \mathrm{E}-05$ \\
$\mathrm{ZrH}_{2} / \mathrm{Tl}$ & $4.2842 \mathrm{E}-05$ & $2.8116 \mathrm{E}-05$ & $4.9787 \mathrm{E}-05$ \\
$\mathrm{Mg}_{2} \mathrm{FeH}_{6} / \mathrm{W}$ & $2.7043 \mathrm{E}-05$ & $3.9798 \mathrm{E}-05$ & $3.2090 \mathrm{E}-05$ \\
$\mathrm{Mg}_{2} \mathrm{FeH}_{6} / \mathrm{U}$ & $3.9219 \mathrm{E}-05$ & $3.4174 \mathrm{E}-05$ & $4.2528 \mathrm{E}-05$ \\
$\mathrm{Mg}_{2} \mathrm{FeH}_{6} / \mathrm{Hf}$ & $2.6952 \mathrm{E}-05$ & $4.7183 \mathrm{E}-05$ & $2.7921 \mathrm{E}-05$ \\
$\mathrm{Mg}_{2} \mathrm{FeH}_{6} / \mathrm{Tl}$ & $4.1505 \mathrm{E}-05$ & $4.7183 \mathrm{E}-05$ & $4.7473 \mathrm{E}-05$ \\
\hline
\end{tabular}

Table 2. Gamma ray flux comparisons for the multilayer models $\left(\right.$ photon $\left./ \mathrm{cm}^{2} \cdot \mathrm{s}\right)$ (relative error $=0.03$ to 0.58$)$.

\begin{tabular}{cccc}
\hline MATERIAL & 2LAYERS & 4LAYERS & 5LAYERS \\
\hline $\mathrm{MgH}_{2} / \mathrm{W}$ & $7.2481 \mathrm{E}-07$ & $9.0051 \mathrm{E}-07$ & $3.0276 \mathrm{E}-06$ \\
$\mathrm{MgH}_{2} / \mathrm{U}$ & $3.1965 \mathrm{E}-07$ & $2.3562 \mathrm{E}-07$ & $1.0421 \mathrm{E}-06$ \\
$\mathrm{MgH}_{2} / \mathrm{Hf}$ & $5.4679 \mathrm{E}-06$ & $1.0662 \mathrm{E}-05$ & $7.8843 \mathrm{E}-06$ \\
$\mathrm{MgH}_{2} / \mathrm{Tl}$ & $4.8865 \mathrm{E}-06$ & $5.1509 \mathrm{E}-06$ & $9.8243 \mathrm{E}-06$ \\
$\mathrm{TiH}_{2} / \mathrm{W}$ & $4.1224 \mathrm{E}-07$ & $7.5272 \mathrm{E}-07$ & $1.5991 \mathrm{E}-06$ \\
$\mathrm{TiH}_{2} / \mathrm{U}$ & $2.1484 \mathrm{E}-07$ & $1.4355 \mathrm{E}-07$ & $6.9543 \mathrm{E}-07$ \\
$\mathrm{TiH}_{2} / \mathrm{Hf}$ & $2.9399 \mathrm{E}-06$ & $6.0002 \mathrm{E}-06$ & $3.0065 \mathrm{E}-06$ \\
$\mathrm{TiH}_{2} / \mathrm{Tl}$ & $2.7103 \mathrm{E}-06$ & $2.6507 \mathrm{E}-06$ & $5.5537 \mathrm{E}-06$ \\
$\mathrm{ZrH}_{2} / \mathrm{W}$ & $2.9719 \mathrm{E}-07$ & $4.9003 \mathrm{E}-07$ & $9.0571 \mathrm{E}-07$ \\
$\mathrm{ZrH}_{2} / \mathrm{U}$ & $9.7461 \mathrm{E}-08$ & $7.9388 \mathrm{E}-08$ & $3.9832 \mathrm{E}-07$ \\
$\mathrm{ZrH}_{2} / \mathrm{Hf}$ & $2.0268 \mathrm{E}-06$ & $3.9144 \mathrm{E}-06$ & $2.1373 \mathrm{E}-06$ \\
$\mathrm{ZrH}_{2} / \mathrm{Tl}$ & $1.9353 \mathrm{E}-06$ & $1.8439 \mathrm{E}-06$ & $3.6887 \mathrm{E}-06$ \\
$\mathrm{Mg}_{2} \mathrm{FeH}_{6} / \mathrm{W}$ & $6.2805 \mathrm{E}-07$ & $8.0215 \mathrm{E}-07$ & $2.2595 \mathrm{E}-06$ \\
$\mathrm{Mg}_{2} \mathrm{FeH}_{6} / \mathrm{U}$ & $2.5956 \mathrm{E}-07$ & $2.4261 \mathrm{E}-07$ & $9.5689 \mathrm{E}-07$ \\
$\mathrm{Mg}_{2} \mathrm{FeH}_{6} / \mathrm{Hf}$ & $4.4049 \mathrm{E}-06$ & $7.9035 \mathrm{E}-06$ & $4.1782 \mathrm{E}-06$ \\
$\mathrm{Mg}_{2} \mathrm{FeH}_{6} / \mathrm{Tl}$ & $3.8071 \mathrm{E}-06$ & $3.5284 \mathrm{E}-06$ & $7.2217 \mathrm{E}-06$ \\
\hline
\end{tabular}

\section{Results}

Table 1 and Table 2 show the multilayer shielding characterization data for combinations of 16 metal hydrides and heavy metals for neutron ray flux and gamma ray flux, respectively. In the single layer model, the neutron ray flux and gamma ray flux for concrete $(2.25 \mathrm{~g} / \mathrm{cc})$ were observed to be $9.6695 \mathrm{E}-05$ and $1.7372 \mathrm{E}-04$, respectively. In the case of $\mathrm{Pb}$ $(11.34 \mathrm{~g} / \mathrm{cc})$, the neutron ray flux and gamma ray flux were confirmed to be $8.2325 \mathrm{E}-05$ and $2.5212 \mathrm{E}-07$, respectively.

In the multilayer model, the lowest neutron flux occurred for the $\mathrm{TiH}_{2} / \mathrm{W}$ multilayer model, while the lowest gamma flux was observed for multilayered structures containing $\mathrm{ZrH}_{2}$ and U. Overall, there was no difference between $\mathrm{MgH}_{2}$, $\mathrm{TiH}_{2}, \mathrm{ZrH}_{2}$, and $\mathrm{Mg}_{2} \mathrm{FeH}_{6}$ for neutron flux. On the other hand, for the gamma ray flux, it was found that adding $\mathrm{W}$ and $\mathrm{U}$ resulted in lower values than adding $\mathrm{Hf}$ and $\mathrm{Tl}$. Therefore, for neutron beams, most of the multilayered structures exhibited shielding efficiencies similar to or higher than that of concrete, whereas all the multilayered structures showed good gamma ray shielding efficiencies when $U$ was added.

In most cases, it was observed that the neutron ray flux and gamma ray flux increased as the number of layers increased. Considering both neutron and gamma rays, the two-layer 
Table 3. Comparison of density, neutron ray flux, and gamma ray flux according to the thickness of $\mathrm{ZrH}_{2}$ and heavy metals (number $/ \mathrm{cm}^{2} \cdot \mathrm{s}$ ) (relative error $=0.03$ to 0.58 ) .

\begin{tabular}{|c|c|c|c|c|}
\hline \multicolumn{2}{|c|}{ Material } & Density $(\mathrm{g} / \mathrm{cc})$ & Neutron flux $\left(\# / \mathrm{cm}^{2} \cdot \mathrm{s}\right)$ & Gamma flux $\left(\# / \mathrm{cm}^{2} \cdot \mathrm{s}\right)$ \\
\hline $5 \mathrm{~cm}$ & $5 \mathrm{~cm}$ & \multirow{2}{*}{12.4} & \multirow{2}{*}{$3.8115 \mathrm{E}-05$} & \multirow{2}{*}{ 7.3336E-08 } \\
\hline $\mathrm{ZrH}_{2}$ & $\mathrm{U}$ & & & \\
\hline $6 \mathrm{~cm}$ & $4 \mathrm{~cm}$ & \multirow{2}{*}{11.04} & \multirow{2}{*}{$3.7153 \mathrm{E}-05$} & \multirow{2}{*}{$2.0551 \mathrm{E}-07$} \\
\hline $\mathrm{ZrH}_{2}$ & $\mathrm{U}$ & & & \\
\hline $7 \mathrm{~cm}$ & $3 \mathrm{~cm}$ & \multirow{2}{*}{9.68} & \multirow{2}{*}{$3.6031 \mathrm{E}-05$} & \multirow{2}{*}{$6.1400 \mathrm{E}-07$} \\
\hline $\mathrm{ZrH}_{2}$ & U & & & \\
\hline $8 \mathrm{~cm}$ & $2 \mathrm{~cm}$ & \multirow{2}{*}{8.32} & \multirow{2}{*}{$3.5489 \mathrm{E}-05$} & \multirow{2}{*}{$1.8533 \mathrm{E}-06$} \\
\hline $\mathrm{ZrH}_{2}$ & $\mathrm{U}$ & & & \\
\hline $9 \mathrm{~cm}$ & $1 \mathrm{~cm}$ & \multirow{2}{*}{6.96} & \multirow{2}{*}{$3.5158 \mathrm{E}-05$} & \multirow{2}{*}{$5.8775 \mathrm{E}-06$} \\
\hline $\mathrm{ZrH}_{2}$ & $\mathrm{U}$ & & & \\
\hline $5 \mathrm{~cm}$ & $5 \mathrm{~cm}$ & \multirow{2}{*}{12.35} & \multirow{2}{*}{$2.8673 \mathrm{E}-05$} & \multirow{2}{*}{$2.7217 \mathrm{E}-07$} \\
\hline $\mathrm{ZrH}_{2}$ & W & & & \\
\hline $6 \mathrm{~cm}$ & $4 \mathrm{~cm}$ & \multirow{2}{*}{11} & \multirow{2}{*}{ 2.7039E-05 } & \multirow{2}{*}{$6.9306 \mathrm{E}-07$} \\
\hline $\mathrm{ZrH}_{2}$ & W & & & \\
\hline $7 \mathrm{~cm}$ & $3 \mathrm{~cm}$ & \multirow{2}{*}{9.65} & \multirow{2}{*}{$2.4485 \mathrm{E}-05$} & \multirow{2}{*}{$1.5847 \mathrm{E}-06$} \\
\hline $\mathrm{ZrH}_{2}$ & W & & & \\
\hline $8 \mathrm{~cm}$ & $2 \mathrm{~cm}$ & \multirow{2}{*}{8.3} & \multirow{2}{*}{$2.3511 \mathrm{E}-05$} & \multirow{2}{*}{$3.8408 \mathrm{E}-06$} \\
\hline $\mathrm{ZrH}_{2}$ & W & & & \\
\hline $9 \mathrm{~cm}$ & $1 \mathrm{~cm}$ & \multirow{2}{*}{6.95} & \multirow{2}{*}{$2.5122 \mathrm{E}-05$} & \multirow{2}{*}{$8.8586 \mathrm{E}-06$} \\
\hline $\mathrm{ZrH}_{2}$ & W & & & \\
\hline
\end{tabular}

structures of $\mathrm{ZrH}_{2} / \mathrm{U}$ and $\mathrm{ZrH}_{2} / \mathrm{W}$ showed excellent neutron beam and gamma ray shielding properties. In order to examine the differences in the shielding properties of $\mathrm{ZrH}_{2} /$ $\mathrm{U}$ and $\mathrm{ZrH}_{2} / \mathrm{W}$ in detail, shielding property simulations were performed in terms of ratio difference.

The two-layer structure of $\mathrm{ZrH}_{2}$ and heavy metal showed better neutron shielding efficiency than that of concrete. In addition, $\mathrm{ZrH}_{2} / \mathrm{W}$ (thickness ratio: 5:5) showed a gamma ray shielding efficiency similar to that of $\mathrm{Pb}$. In the case of $\mathrm{U}$, the gamma ray shielding efficiency exceeded that of $\mathrm{Pb}$ at a thickness ratio of 6:4. For $\mathrm{ZrH}_{2} / \mathrm{U}$ (thickness ratio: 5:5), the shielding efficiency was $254 \%$ that of concrete for neutron rays and $344 \%$ that of $\mathrm{Pb}$ for gamma rays at $1 \mathrm{MeV}$. When using $\mathrm{W}$, the corresponding numbers were $337 \%$ and $92.6 \%$ at $1 \mathrm{MeV}$. Here, the shielding efficiency was calculated based on the neutron ray flux and gamma ray flux of concrete and $\mathrm{Pb}$. As a result, $\mathrm{U}$, which has a higher density than $\mathrm{W}$, showed excellent gamma ray shielding efficiency. As the thickness of the heavy metal increased, the gamma ray flux decreased.

\section{Conclusion}

In order to identify suitable shielding materials that can replace $\mathrm{Pb}$ and concrete, new materials were explored using the Monte Carlo simulation code MCNP6. A three-axis shielding model measuring $10 \mathrm{~cm}$ in each direction was set up, and the shielding properties of various metal hydridebased materials were evaluated and compared. The results showed that a single-layer shielding structure is disadvantageous as it does not shield the secondary gamma rays that are generated by the metal hydride. Shielding materials with a multilayered structure consisting of metal hydride and heavy metals exhibited shielding efficiencies equal to or better than those of existing shielding materials. In particular, a multilayer shield structure consisting of $\mathrm{ZrH}_{2} / \mathrm{U}$ and $\mathrm{ZrH}_{2} / \mathrm{W}$ showed neutron ray and gamma ray shielding efficiencies of 254 and $337 \%$ of those of concrete, and 344 and $92.6 \%$ of those of $\mathrm{Pb}$, respectively, at $1 \mathrm{MeV}$. Thus, these multilayers can be used to replace concrete and $\mathrm{Pb}$ as neutron and gamma ray shielding materials in nuclear reactors and thermocouples. 


\section{Author Contributions}

The manuscript was written with contributions from all authors. All authors have given approval to the final version of the manuscript.

\section{Notes}

The authors declare no competing financial interest.

\section{Data Availability}

All the authors agree to provide the datasets generated during and/or analyzed during the current study on reasonable request.

\section{Acknowledgment}

This work was supported by Radiation Technology R\&D program through the National Research Foundation of Korea funded by the Ministry of Science and ICT (NRF2017M2A2A4A01071249).

\section{REFERENCES}

1. Dubrova. Y. E., Nesterov. V. N., Krouchinsky. N. G., Ostapenko. V. A., Neumann. R., Neil. D. L., and Jeffreys, Nature. 380, 683 (1996).

2. Kinoshita. N., Sueki. K., Sasa. K., Kitagawa. J. I., Ikarashi. S., Nishimura. T., and Sato. M., Proc. Natl. Acad. Sci. U.S.A. 108, 19526 (2011).
3. Singh. K. J., Kaur. S., and Kaundal. R. S., Radiat. Phys. Chem. 96, 153, (2014).

4. Cho. H-S. and Kim S-S, Korean J. Met. Mater. 57, 741 (2019).

5. Choi. Y. Korean J. Met. Mater. 58, 639 (2020).

6. Limkitjaroenporn. P., Kaewkhao. J., Limsuwan. P., and Chewpraditkul. W., J. Phys. Chem. Solids. 72, 245 (2011).

7. Sing., V. P., Badiger. N. M., and Kaewkhao, J., J. NonCryst. Solids. 404, 167 (2014).

8. Lee. C. M., Lee. Y. H., and Lee. K. J., Prog. Nucl. Energy. 49, 303 (2007).

9. Elbio. C., Florian. G., Burkhard. S., and Harald. T., Nucl. Instrum. Methods Phys. Res. 1, 77 (2011).

10. Dong. M. G., El-Mallawan., R., Sayyed. M. I., and Tekin. H. O., Radiat. Phys. Chem. 141, 172 (2017).

11. Sohrabpour. M., Hassanzadeh. M., and Shahriari. M., Appl. Radiat. Isot. 57, 537 (2002).

12. Tekin. H. O., Singh. V. P., and Manici. T., Appl. Radiat. Isot. 121, 122 (2017).

13. Tekin. H. O., Sayyed. M. I., Manici. T., and Altunsoy. E. E., Mater. Chem. Phys, 211, 9 (2018).

14. Piotrowski. T., Tefelski. D., Polański. A., and Skubalski. J., Cent. Eur. J. Eng. 2, 296 (2012).

15. Tekin. H. O., Sayyed. M. I., Altunsoy. E. E., and Manici. T., Dig. J. Nanomater. Bios, 12, 861 (2017).

16. Goorley. T., James. M., Booth. T., Brown. F., Bull. J., Cox. L. J., and Zukaitis. T., Nucl. Technol. 180, 298 (2012).

17. Andrews. M. T., Goorley. J. T., Corcoran. E. C., and Kelly. D. G., Trans. Am. Nuclear Soc, 110, 490 (2014).

18. Kang. W. G., Pyo. S. H., Alkhuraiji. T. S., Han. B. S., and Kang. C. M., J Xray Sci Technol. 25, 505 (2017). 